\title{
Fatigue Life Enhancement of Transverse and Longitudinal T- Joint on Offshore Steel Structure HSLAS460G2+M using Semi- automated GMAW and HFMI/PIT
}

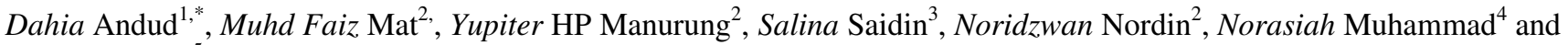 \\ Martin Laitner ${ }^{5}$ \\ ${ }^{1}$ University Kuala Lumpur Malaysia France Institute Bandar Baru Bangi, Selangor, Malaysia \\ ${ }^{2}$ Faculty of Mechanical Engineering, Universiti Teknologi MARA (UiTM), Shah Alam, Selangor, Malaysia \\ ${ }^{3}$ Nusantara Technologies Sdn Bhd, Selangor, Malaysia \\ ${ }^{4}$ Politeknik Sultan Salahuddin Abdul Aziz Shah (PSA), Shah Alam, Selangor, Malaysia \\ ${ }^{5}$ Montanuniversität Leoben, Chair of Mechanical Engineering, Austria
}

\begin{abstract}
This research deals with a method and procedure for enhancing the structural life of the commonly used steel structure in oil and gas industries HSLA S460G2+M with a thickness of $10 \mathrm{~mm}$. The type of joint and welding process is T-joint with transverse and longitudinal attachment welded using semiautomated GMAW. Filler wire ER80S-Ni1 and mixed shielding gas $\left(80 \% \mathrm{Ar} / 20 \% \mathrm{CO}_{2}\right)$ is used as material consumables. At first, the best suitable welding parameters are comprehensively investigated, prepared, tested and qualified according to welding procedure specification (WPS) qualification requirements. Further, the weld toe is treated by using HFMI/PIT with a frequency of $90 \mathrm{~Hz}, 2 \mathrm{~mm}$ pin radius and air pressure of 6 bars. In accordance with the recommendation of the International Welding Institute (IIW), fatigue test is conducted using constant amplitude loading with the stress ratio of 0.1 and loading stresses from $55 \%$ to $75 \%$ of the yield strength of the material. Finally, the results of the fatigue experimental are compared with the fatigue recommendation of as-welded and HFMI/PIT of IIW as well as the untreated raw material. As a conclusion, it is observed that the fatigue life is increased up to $300 \%$ compared to IIW and $70 \%$ to as-welded. It is also obvious that treated transverse T-joint shows significant improvement than the longitudinal attachment.
\end{abstract}

\section{Introduction}

In a construction of bridges, steel tower, oil and gas platform, the use of semi-automated Gas Metal arc welding (GMAW) processes could not be neglected, since numerous components of these structures are joined using this type of fusion welding. Even though semi-automated GMAW is lack of consistency as compared to automated welding, this process is still relevant to the fabrication sector due to cost-effective, versatile and portable. In addition, continuous development of the high-tech semi-automated welding machine which is nowadays supplied with the actual current parameter for certain steel type and thickness and also equipped with the new innovation of welding support such as force arc and cold arc [1]. This high-tech welding machine not only provides the various selection of welding modes, but help the welder to make high quality of welded joint which less influenced by welding defects such as undercut and porosity.

Fatigue failures of the welded connection frequently initiated at the weld toe due to the welding defects and geometrical notches as well as the residual stresses and load histories, etc. [2]. The fatigue strength enhancement of the welded joint can be achieved by using conventional methods such as burr-grinding, TIG dressing and hammer peening for geometry improvement [3]. However, nowadays the HFMI tool is widely used to eliminate the geometry hot spot as well as for the residual stresses modification as documented in IIW commission XIII [4]. Geometry modification will lessen the size of the weld toe flaws and the local stress concentration, while the residual stress adjustment will have brought compressive residual stress in the treated area. The adjustment increased the fatigue life of steel up to $30 \%$ and $50 \%$ for high strength steel [4].

Fatigue life enhancement using high-frequency mechanical impact (HFMI) of the welded joint of high strength steel is broadly discussed by scientists. Some of the HFMI technology methods that be acquainted with IIW are the Ultrasonic Impact Treatment (UIT), Ultrasonic Peening Treatment (UPT), High-Frequency Hammer Peening (HFHP), High-Frequency Impact Treatment (HiFIT) and pneumatic Impact treatment (PIT) [4-8]. The working standard of these HFMI is identical, which is using cylinder-shaped indenter that

Corresponding author: muhdfaiz7062@salam.uitm.edu.my 
augmented against a structure with high frequency. HFMI deformed plastically the material surface, local geometry and induced compressive residual stress in the treated region.

The fatigue life enhancement method of this research is dealing with HFMI pneumatic impact treatment (HFMI/PIT) method on the commonly used steel structure of oil and gas industries HSLA S460G2+M with a thickness of $10 \mathrm{~mm}$. The posttreatment is using pin indenters of $2 \mathrm{~mm}$ pin radius against the weld toe with a high frequency of $90 \mathrm{~Hz}$ and 6 bars of pneumatic pressure, while the treatment angle is between $30^{\circ}$ to $60^{\circ}$ and feed speed around $5 \mathrm{~cm}$ to 20 $\mathrm{cm}$ per minutes. The treatment was conducted against the weld toe of the transverse and longitudinal T-joint weld of S460G2+M. A severe plastic deformation and beneficial compressive residual stresses induced at the weld toe and harden the material surface as well as improved the weld toe shape. Nowadays, HFMI/PIT has been recognized as an effective means for fatigue improvement, especially for high-strength steels.

Previous work in HFMI/PIT post weld mechanical treatment of welded joints of HSLA has shown impressive improvement in the fatigue life of the welded joint. Leitner et al [9] studied the effect of HFMI/PIT on the butt joint, transverse and longitudinal welds attachment on 5mm HSLA S690. They found that the fatigue life of the HFMI/PIT treated specimen is almost similar to the fatigue strength of the untreated base material. It shows the FAT-class increased by a factor of 1.2 for butt joint, 1.6 for transverse and 2.5 for longitudinal attachment as compared to the as-welded condition. The fatigue crack initiation also is shown to shift from end of weld seam to the heat-affected zone area of the base material after HFMI/PIT treatment. They also evaluated the welded joint using effective notch stress approach and found that the butt joint has lower stress concentration factor which made it higher endurance strength as compared to the $\mathrm{T}$-joint and the longitudinal attachment. They [10] also investigated the effect of HFMI/PIT on the fatigue life of welded HSLA S690 and S960 with common structural steel S355. They found that the common construction steel S355 reaches for all three specimen types about $85 \%$ of the base material fatigue stress range and also for the high strength steel S690 and S960 are almost equal to the base material fatigue behavior. In the high-cycle fatigue region, the post-treatment shows a significant enhancement compared to the finite life time regime. In their analysis [11] using Abaqus for HFMI treatment, they concluded that an assessment of the obtained residual stress condition with the radiographic measurement shows a good arrangement with up to fifteen percent differences for the as-welded and up to ten percent for the HFMI- treated state. They also revealed that, a local hardening and the attendance of compressive residual stresses due to HFMI led to an extension of the crack initiation phase that reduce the amount of crack propagation in relation to the total lifetime. Analysis [12] of the crack dissemination of the joined structure of the carbon steel S355 and naturalize using post-treatment HFMI/PIT also found that the fatigue life of the specimen has a decent arrangement with the earlier analysis. Furthermore, Leitner investigated the influence of the effective stress ratio and reveals that the effective stress ratio may be related to the fundamental change in the local residual stress state [13]. Especially the HFMI treatment leads to a reduction of the local residual stress condition.

Manurung et al. [14] applied the HFMI/PIT to enhance the fatigue life of the friction stir welding. They found that HFMI/PIT has a significant effect on the hardness which is $75 \mathrm{HV}$ for as welded and 95HV after the treatment. The fatigue life of the treated specimen also increased almost nine times as compared to as welded specimen. Schäfers et al. [15] studied the residual stress of welded joint treated with Pneumatic Impact Treated (PIT) by using X-ray diffraction or hole drilling method and compared with the residual stress state in a numerical simulation. They found that the experimental values for HFMI-treated joints showing a good agreement with numerical. Most of the HFMItreated data points exceed the recommendation. J. Foehrenbach et al [16] studied the effect of HFMI/PIT using numerical and experimental methods on steel grade S355J2H.They directed an extensive X-ray and neutron diffraction for residual stress measurement. They found that the numerical evaluated combined hardening model equal very well with the experiments. Also, the compressive residual stresses equivalent to base material yield strength after the HFMI/PIT treatment. It was exposed that the material hardening model has a great influence on the replicated residual stresses.

The effectiveness of HFMI/PIT technology to improve the fatigue life of the welded structure was inspired the scientist to write the Guideline for Fatigue Strength Improvement of Steel Structures by HighFrequency Mechanical Impact (HFMI) [17] and also the application and quality assurance for HFMI [18].In addition, the guideline on weld quality in relationship to fatigue strength also available [19]. These guidelines and recommendations nowadays were included in IIW collection accordingly.

Based on previously worked shown that the technology fatigue enhancement method using HFMI/PIT produces an excellent result for fatigue improvement especially for high strength steel. However, the literature review of fatigue data concerning the effect of HFMI/PIT on the fatigue life of commonly offshore steel HSLA S460G2+M that specially designed for use in a tough location is still not available today. With this motivation, the identification of the best welding parameters for HSLA S460G2+M and fatigue exploration on the as-welded and treated HFMI/PIT for transverse and longitudinal $\mathrm{T}$-joint specimen has been significantly conducted.

\section{Semi Automated Welding Parameter Identification for HSLA S460G2+M}

The HSLA S460G2+M steel is broadly used in the manufacture of fixed offshore structures such as oil rigs 
and service platforms [20]. It was made through the Thermo-Mechanically Controlled Processed (TMCP) condition. It has a minimum yield strength of $460 \mathrm{MPa}$, excellent mechanical properties and good weldability. Generally, the usage of this HSLA steel in the industry is to reduce the weight of structural. Table 1 and 2 depict its chemical composition and mechanical properties respectively [21].

Table 1. The chemical composition of HSLA S460G2+M steel

\begin{tabular}{|c|c|c|c|c|c|c|c|c|}
\hline $\begin{array}{c}\mathrm{C} \\
\mathbf{\%}\end{array}$ & $\begin{array}{c}\mathbf{C u} \\
\mathbf{\%}\end{array}$ & $\begin{array}{c}\mathrm{Mn} \\
\mathbf{\%}\end{array}$ & $\begin{array}{c}\mathbf{V} \\
\mathbf{\%}\end{array}$ & $\begin{array}{c}\mathbf{S i} \\
\mathbf{\%}\end{array}$ & $\begin{array}{c}\mathrm{Al} \\
\mathbf{\%}\end{array}$ & $\begin{array}{c}\mathbf{C r} \\
\mathbf{\%}\end{array}$ & $\begin{array}{c}\mathbf{N b} \\
\mathbf{\%}\end{array}$ & $\begin{array}{c}\mathbf{N i} \\
\mathbf{\%}\end{array}$ \\
\hline 0.1 & 0.11 & 1.62 & $\begin{array}{c}0.1 \\
0\end{array}$ & 0.6 & $\begin{array}{c}0.03 \\
2\end{array}$ & 0.10 & $\begin{array}{c}0.01 \\
2\end{array}$ & $\begin{array}{c}0.0 \\
9\end{array}$ \\
\hline
\end{tabular}

Table 2. Mechanical properties of HSLA S460G2+M steel

\begin{tabular}{|c|c|}
\hline \multicolumn{2}{|c|}{ HSLA S460G2+M } \\
\hline Thickness, $\mathrm{t}$ & $\mathrm{t}<16$ \\
\hline Yield strength (Ys) & $460 \mathrm{MPa}(\mathrm{min})$ \\
\hline Tensile Strength (UTS) & $540-700 \mathrm{MPa}$ \\
\hline Ys/UTS & Max.0.93 \\
\hline CVN $\left(-40^{\circ} \mathrm{c}\right)$ & $>$ 60J transverse \\
\hline Elongation. $\%$ & $17 \%$ \\
\hline
\end{tabular}

Assortment the correct welding parameters for HSLA materials are critical due to its weldability is complicated as compared with the conventional carbon steel. Precise joint design, current and voltage, filler wire and shielding gas are important. Thus, to find the suitable welding parameters for HSLA S460G2+M, the welding procedure specification qualification (WPQ) is conducted in accordance with the specification for welding procedure and performance qualification [22]. Preliminary welding procedure specification (pWPS) is conducted before the WPS qualification. It is a manuscript containing welding parameter variables of the welding procedure that needs to be practiced before establish the actual welding procedure specification (WPS). The variables in pWPS, frequently obtained from manufacturing recommendation and from the experience GMAW welder. Altogether the essential variable requirement such as joint preparation, filler metal, shielding gas, testing, etc. ought to be included accordingly [23]. Table 3 indicates some of the essential variables for welding procedure specification qualification in pWPS.

Table 3. Summary of essential variables for preliminary welding procedure specification (pWPS)

\begin{tabular}{|c|c|}
\hline Material: & HSLA S460G2+M \\
\hline $\begin{array}{r}\text { Size }(\mathbf{L x W x T}) \\
\text { mm: }\end{array}$ & $(300 \times 180 \times 10) \mathrm{mm}$ \\
\hline Joint design: & Butt Joint (Single V groove) \\
\hline Groove angle: & $60^{\circ}$ \\
\hline Roof face: & $1.5-2.5 \mathrm{~mm}$ \\
\hline Roof gap: & $2-2.5 \mathrm{~mm}$ \\
\hline Welding type: & GMAW \\
\hline Shielding gas: & $80 \% \mathrm{Ar}+20 \% \mathrm{CO}_{2}$ \\
\hline Filler metal: & ER80S-Ni1 \\
\hline $\begin{array}{l}\text { Current and } \\
\text { voltage: }\end{array}$ & $\begin{array}{l}\text { Root }=90-100 \text { Amp, } 18-22 \mathrm{~V} \\
\text { Hot pass }=180-230 \text { Amp, } 18-22 \mathrm{~V} \\
\text { Capping }=180-230 \text { Amp, } 18-22 \mathrm{~V}\end{array}$ \\
\hline
\end{tabular}

As part of the requirement of the WPS qualification, the tensile tests were conducted after the welding fabrication. The tensile test results of the welded HSLA S460G2+M are presented in Table 4. There are two samples for the tensile test. The sample of T1 ruined in base metal and the sample $\mathrm{T} 2$ ruined in the HAZ area as shown in Figure 1. T1 attained $600 \mathrm{MPa}$ while T2 attained around $584 \mathrm{MPa}$, which is both samples strength is compatible with the raw material strength range $(540 \mathrm{MPa}-700 \mathrm{MPa})$ based on the acceptance criteria in section 4 clause 4.9.3.5 of AWS D1[24].

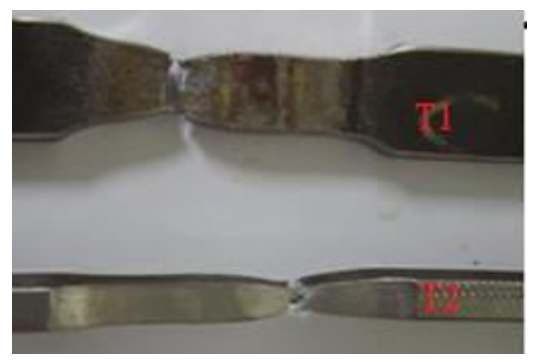

Fig. 1. Tensile test of the welded sample of HSLA S460G2+M

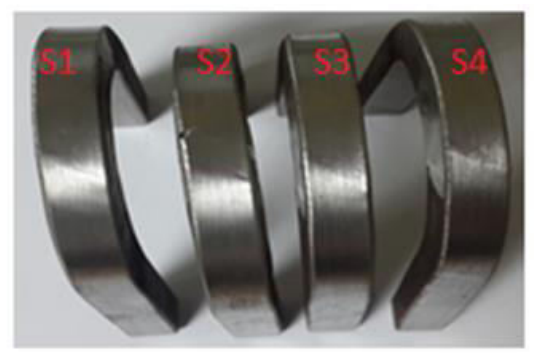

Fig. 2. Bend test samples of the welded HSLA S460G2+M

There were four samples designated as S1, S2, S3, and S4 for side bend test as shown in Table 5. The side bend test is directed to guarantee that the weld has appropriately merged with the parent metal of S460G2+M and that the weld itself does not comprise any defects that might cause it to fail when it experience bending stresses in the future. The side bend test specimens were designated as $\mathrm{S} 1, \mathrm{~S} 2, \mathrm{~S} 3$, and $\mathrm{S} 4$ as presented in Table 5. The completed side bend test specimens in ' $U$ ' shape are displayed in Figure 2. It is clear that, no sign of cracks and defects in the bent areas of sample S1, S3, and S4, butt a minor crack less than $3 \mathrm{~mm}$ appeared on the corner bent area of sample S2 due to the mechanical damage prior the preparation of the sample. However, according to the acceptance criteria in AWS D1.1 clause 4.9.3.3, the crack below $3 \mathrm{~mm}$ at the bent corner is still acceptable [25] otherwise the affected sample shall be replaced with new sample. The absent of discontinuities on the bend samples showed the welding current and techniques used for welding process were in good blend.

\section{Post Weld Mechanical Treatment using HFMI/PIT treatment and Fatigue test based on IIW Recommendation}

Post weld mechanical treatment using HFMI/PIT in general have significant advantages to welded steel. It is well known as 'Anti-aging' which is capable to eliminate the hot spot, induced compressive residual stress in the treated region, reduce the distortion due to 
welding, increase surface hardness as well as prevention from stress corrosion cracking.

The design of the HFMI/PIT tool also is very userfriendly. It was designed for better accessibility, light, simple programming for frequency and pressure, variable sizes and design of the pins, air cooling for pins, very low vibration level (approx. $5 \mathrm{~m} / \mathrm{s}^{2}$ ), low voltage operation $(24 \mathrm{~V})$ and can be applied in confined spaces. By all these advantages the HFMI/PIT is a leader of it class. The Complete equipment of the HFMI/PIT is shown in Figure 3.

The post weld mechanical treatment variables in this research were $90 \mathrm{~Hz}$ of frequency, $2 \mathrm{~mm}$ pin radius and 6 bars of air pressure with overall speed around 20$25 \mathrm{~cm} / \mathrm{min}$. The operating procedures of the HFMI/PIT are in accordance to the IIW recommendations for the HFMI treatment [26].

The weld specimens were underwent fatigue test using a servo-hydraulic INSTRON fatigue machine with a dynamic load capacity of $250 \mathrm{kN}$. The constant amplitude loading was used with the fatigue loading ratio of $\mathrm{R}=0.1$. The fatigue test was conducted using various fatigue loadings from $55-75 \%$ of the yield strength of the material S460G2+M. The fatigue results were assessed using a nominal stress approach [27].

Table 4. Tensile test results of welded S460G2+M

\begin{tabular}{|c|c|c|}
\hline \multirow{2}{*}{ Properties } & \multicolumn{2}{|c|}{ As welded } \\
\hline & T1 & T2 \\
\hline Width (mm): & 20.15 & 20.12 \\
\hline Thickness (mm): & 9.98 & 9.97 \\
\hline $\begin{array}{l}\text { Cross-sectional area (A) } \\
\left(\mathrm{mm}^{2)}:\right.\end{array}$ & 201.10 & 200.60 \\
\hline Yield Load (N): & 107580.28 & 107704.53 \\
\hline Yield stress $\left(\mathrm{N} / \mathrm{mm}^{2}\right)$ : & 534.97 & 536.92 \\
\hline Maximum Load (N): & 120785.98 & 118238.91 \\
\hline Tensile strength $\left(\mathrm{N} / \mathrm{mm}^{2}\right)$ : & 600.64 & 589.44 \\
\hline Position of Fracture: & Broke at $\mathrm{BM}$ & $\begin{array}{c}\text { Broke at } \\
\text { HAZ }\end{array}$ \\
\hline
\end{tabular}

Table 5. Bend test results of welded HSLA S460G2+M

\begin{tabular}{|l|l|l|}
\hline $\begin{array}{l}\text { Diameter of } \\
\text { Former: }\end{array}$ & $50.8 \mathrm{~mm}$ \\
\hline Angle of Bend: & $180^{\circ}$ \\
\hline Type of Bend: & Result & Remarks \\
\hline Side Bend (S1): & Acceptable & Defect free \\
\hline Side Bend (S2): & Acceptable & Defect free \\
\hline Side Bend (S3): & Acceptable & $\begin{array}{l}\text { Visible defect around } \\
2.63 \mathrm{~mm} \text { at weld metal }\end{array}$ \\
\hline Side Bend (S4): & Satisfactory & Defect free \\
\hline
\end{tabular}
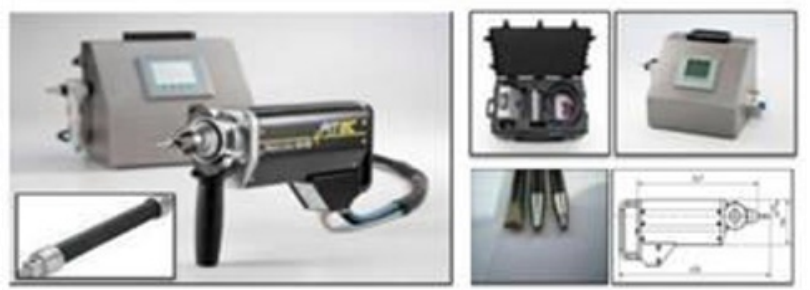

Fig. 3. HFMI/PIT Equipment Set

\section{Results and Discussion}

\subsection{Fracture surface Analysis}

A comparison of the macro fracture mechanic of the transverse and longitudinal $\mathrm{T}$-joint after fatigue test are shown in Figure 4. Both specimens were tested using the same level of fatigue loading which is $347 \mathrm{MPa}$ of its yield strength. The inspection is focused on the fatigue cracking propagation $(\mathrm{A})$ and the rupture part $(\mathrm{B})$ which is depicted in Figure 4a-d. The as-welded specimens for both joint shows a typically crack initiation appeared along the weld toe line and at the end of weld seam [12]. However, due to an even conversion between the weld toe and base metal after the HFMI/PIT treatment, the stress concentration is shifted from weld toe to the base metal area as indicated in Figure $3 \mathrm{~b}$. Thus, this inspection reveals that not only HFMI/PIT eliminate the stress concentration at the weld toe but also capable to immigrate the crack initiation to another location.

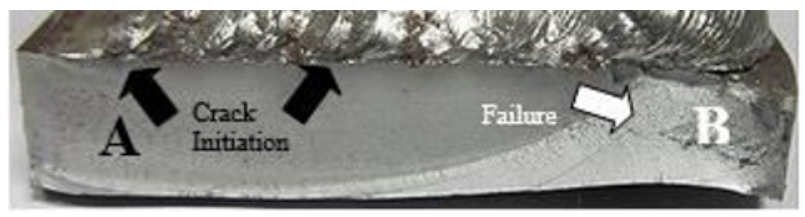

a. As-welded transverse $\mathrm{T}$-joint, the crack initiation appeared along the weld toe line.

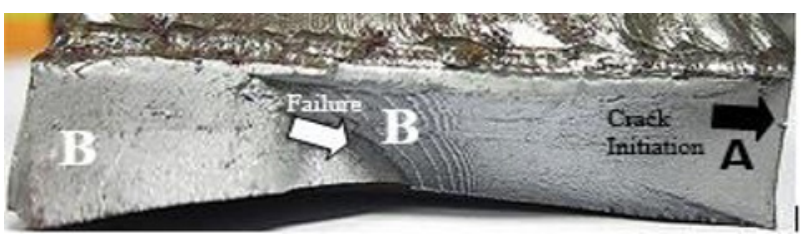

b. HFMI/PIT treated transverse T-Joint, the crack initiation appeared in the base metal

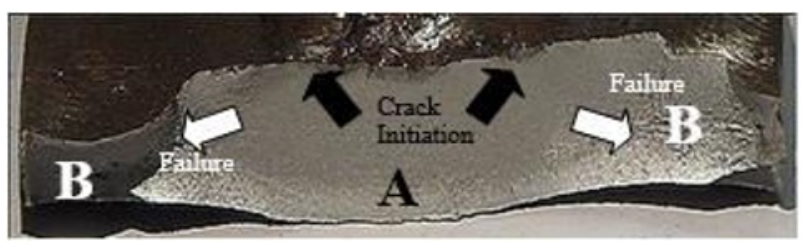

c. As-welded longitudinal T-joint, the crack initiation appeared at the end of the weld seam.

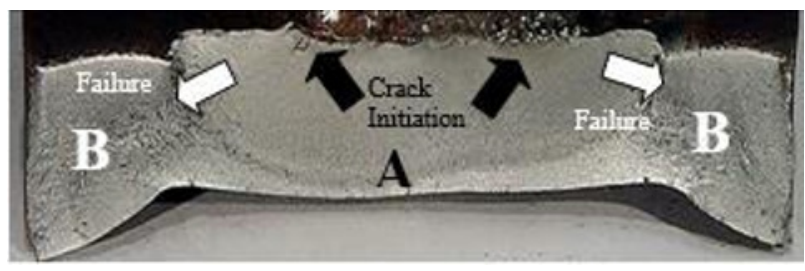

d. HFMI/PIT treated Longitudinal T-joint, the crack initiation appeared at the end of the weld seam

Fig. 4. The fracture surface of transverse and longitudinal TJoint weld of as-welded and HFMI/PIT condition 


\subsection{Fatigue Life of Transverse and Longitudinal T-Joint}

The S-N curve of the as-welded and HFMI/PIT treated of the transverse and longitudinal T-joint weld are shown in Figure 5 and 6 respectively. As indicated in the S-N curve both fatigue strengths of the as-welded and HFMI of the offshore structure S460G2+M either transverse or longitudinal T-joint weld are above the IIW fatigue strength recommendation for as-welded and HFMI. However, still below the fatigue strength of the base material.

A significant improvement in fatigue strength due to HFMI/PIT is seen in treated transverse T-joint of $\mathrm{S} 460 \mathrm{G} 2+\mathrm{M}$ which is the fatigue resistance at two million load-cycles increases by $72 \%$ from $149 \mathrm{MPa}$ for the aswelded up to $259 \mathrm{MPa}$ for the HFMI-treated condition. The increment is equivalent to 1.7 bonus factor. When comparing with the IIW as-welded recommendation the fatigue strength of the HFMI/PIT specimen increase by a factor of 3.2 which is up to $300 \%$ increment. In addition, the slope $\mathrm{k}$ in the finite lifetime region enhances to $\mathrm{m}=6.35$ as compared to the conventional slope of the HFMI/PIT treated of $m=5$.

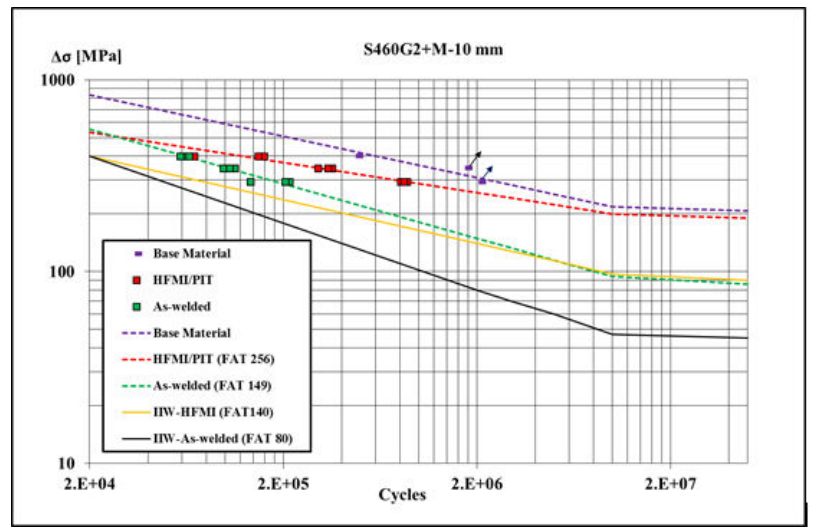

Fig. 5. S-N curve for transverse T-joint weld

An image of the S/N-curve of the longitudinal Tjoint weld of S460G2+M is shown in Figure 6. Fundamentally, the similar trends are noticeable for the HFMI/PIT sample. The HFMI/PIT action primes to a crucial augmentation of the fatigue performance as compared to the as-welded state. The fatigue strength at two million load-cycles increases up by $54 \%$, from 146 MPa for the as-welded to $255 \mathrm{MPa}$ for the HFMI-treated specimens. In addition, the slope $\mathrm{k}$ in the finite lifetime region enhances to $\mathrm{m}=5.89$ as compared to the conventional slope of the HFMI/PIT treated of $m=5$ [24].

The evaluation according to the nominal stress approach indicates an increase of the fatigue strength due to the HFMF/PIT technology for all two investigated weld seam geometries. The evaluated FAT class and benefit factors when using the nominal stress as assessment approach are summarized in Table 6 accordingly.

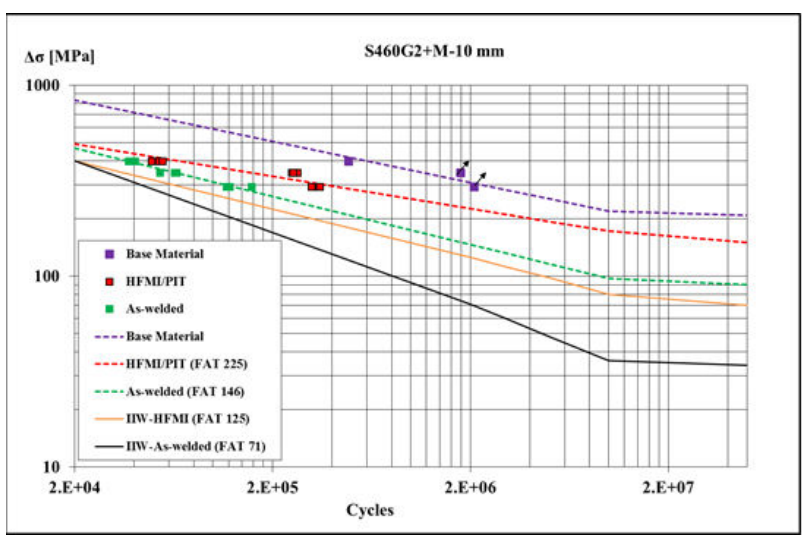

Fig. 6. S-N curve for longitudinal T-joint weld

Table 6. Summary of fatigue strength increment due to HFMIPIT for the transverse and longitudinal T-joint weld

\begin{tabular}{|c|c|c|c|}
\hline & $\begin{array}{c}\text { As-welded } \\
\text { FAT (m) }\end{array}$ & $\begin{array}{c}\text { HFMI/PIT } \\
\text { FAT (m) }\end{array}$ & $\begin{array}{c}\text { Bonus } \\
\text { increment } \\
\text { factor }\end{array}$ \\
\hline $\begin{array}{c}\text { Transverse T- } \\
\text { joint weld }\end{array}$ & $\begin{array}{c}149 \mathrm{MPa} \\
(3.52)\end{array}$ & $\begin{array}{c}256 \mathrm{MPa} \\
(6.35)\end{array}$ & 1.7 \\
\hline $\begin{array}{c}\text { Longitudinal T- } \\
\text { joint weld }\end{array}$ & $\begin{array}{c}146 \mathrm{MPa} \\
(3.95)\end{array}$ & $\begin{array}{c}225 \mathrm{MPa} \\
(5.89)\end{array}$ & 1.5 \\
\hline
\end{tabular}

\section{References}

1. www.ewm-group.com/en/products/weldingmachines-ewm.html.

2. Berto, Filippo, A.Vinogradov, and S.Filippi, Int. J. Fatigue, 101, 371-384 (2017):

3. P.J.Haagensen, S.J.Maddox, IIW Recommendations on Post Weld Fatigue Life Improvement of Steel and Aluminium Structures, (W. Pub. Ltd., Camb. 2013).

4. G. Marquis and Z. Barsoum, XIII-2453r1 (2013).

5. R. T. Yekta, K. Ghahremani, and S. Walbridge, Int. J. Fatigue, 55, 245-256 (2013).

6. K. Yuan. Dissertation, Grad. Sc. Eng, Yo. Nat. Uni. (Sept. 2015).

7. P. S. Hakimi and M. Al-Emrani, Post weld treatment - Implementation on bridges with special focus on HFMI, (Chal.Uni.Tech Rep. 2014).

8. F. B. Yalchiner and Z. Barsoum, Procedia Struct. Integr., 5, 377-384 (2017).

9. M. Leitner, M. Stoschka, R. Schanner, and W. Eichlseder, FME Trans., 40, 3, 99-104 (2012).

10. M. Leitner, M. Stoschka, and W. Eichlseder, IIW Document XIII-2416-12 (2012).

11. M. Leitner, D. Simunek, S. F. Shah, and M. Stoschka, Adv. Eng. Softw., 0, 1-11 (2015).

12. M. Leitner and M. Stoschka, J. Eng and Technol, 1, 3, 80-90 (2013).

13. M. Leitner, Z. Barsoum, and F. Schäfers, Weld. World, 60, 3, 581-592 (2016). 
14. Y. H. P. Manurung, M. A. Mohamed, and A. Z. Abidin, Int. J. Adv. Manuf. Technol., 90, 9, 35753583 (2017).

15. F. Schäfers, P. Gerster, and M. Leitner, XIII-WG2146, IIW (2015).

16. J. Foehrenbach, V. Hardenacke, and M. Farajian, Weld. World, 60, 4, 749-755 (2016).

17. G. B. Marquis and Z. Barsoum, Procedia Eng., 66, 98-107 (2013).

18. P. Gerster, F. Schäfers, and M. Leitner, Document XIII-WG2, IIW, 138, 1-11 (2013).

19. G. M. Bertil Jonsson, G. Dobmann, A. F. Hobbacher, M. Kassner, Spr. Int. Publ (2016).

20. J. Billingham, J. V. Sharp, J. Spurrier, and P. J. Kilgallon, Rev. Perform. high strength steels used offshore., (ISBN 071762205 3. 2003).

21. http://ds.arcelormittal.com/repo/Technical Data Sheets/Plates - S460G2 M.pdf.

22. AWS D1.1, B2.1 Specification for Welding Procedure and Performance Qualification (2004).

23. AWS D1.1/D1.1M, Section 4.8 the essential variable limitations (2015).

24. AWS D1.1/D1.1M, Section 4 clause 4.9.3.5, the acceptance criteria (2015).

25. AWS D1.1/D1.1M, Section 4 clause 4.9.3.3, the acceptance criteria (2015).

26. Z. B. Marquis, Gary B, IIW Recommendations for the HFMI treatment (2016).

27. A. Hobbacher, IIW Doc. IIW-1823-07 ex XIII2151r4-07/XV-1254r4-07, 1-149 (2008). 